\title{
The unmet needs for modern family planning methods among postpartum women in Sub-Saharan Africa: a systematic review of the literature
}

\author{
Jumaine Gahungu ${ }^{1 *}$, Mariam Vahdaninia² and Pramod R. Regmi ${ }^{3}$
}

\begin{abstract}
Background: Sub-Saharan Africa has the highest fertility rate in the world, with the highest unmet need for family planning (FP). Yet, there is a lack of knowledge about the determinants for non-utilisation of modern contraceptive methods among women of reproductive age. This systematic review of literature assessed factors affecting the unmet need and reasons for non-utilisation of modern contraceptive methods during the postpartum period in Sub-Saharan African women.

Methods: An online literature search was conducted in several databases: MEDLINE, Cochrane Review, PubMed, Elsevier's Science Direct and Web of Science. The search was completed by hand searching. Data were extracted and summarised using the Arksey and O'Malley methodology.

Results: In total, 19 studies were included; one qualitative study, seventeen quantitative, and one used a mixedmethods approach. Studies were conducted in Ethiopia $(n=11)$, Nigeria $(n=3)$, Kenya $(n=2)$, Malawi $(n=2)$ and Uganda $(n=1)$. Factors affecting the unmet need for modern contraceptive methods were described at three levels: (a) individual; (b) household; and (c) healthcare facility level. Reasons for non-use of FP included: fear of side effects; husband's disapproval; the absence of menses; abstinence; and low perception of risk of pregnancy.

Conclusion: Unmet needs in postpartum FP in women from Sub-Saharan Africa were associated with health-system and socio-demographic determinants. We suggest that there is a need to improve the awareness of modern contraceptive methods through effective interventions. Further research is needed for under-studied countries in this continent.
\end{abstract}

Keywords: Family planning, Contraception, Unmet need, Modern contraception methods, Postpartum, Women of reproductive age

\section{Background}

Available evidence has shown that short birth spacing puts the mother and both the newborn and the preceding child at high risk of morbidity and mortality [1]. It is gradually being recognised there is a high unmet need

\footnotetext{
*Correspondence: jimmygah@gmail.com

${ }^{1}$ Martin Luther King University, Bujumbura, Burundi

Full list of author information is available at the end of the article
}

for postpartum family planning (PPFP); and that relying on breastfeeding alone may expose women to the risk of unwanted pregnancies [2,3]. Sub-Saharan African (SSA) countries have the highest unmet need for PPFP [4], whilst there is a recognised knowledge gap in PPFP in SSA countries [5].

Women with unmet need for PPFP can be defined as all sexually active and fecund women (legally married or in a consensual union) wishing to prevent unintended original author(s) and the source, provide a link to the Creative Commons licence, and indicate if changes were made. The images or other third party material in this article are included in the article's Creative Commons licence, unless indicated otherwise in a credit line to the material. If material is not included in the article's Creative Commons licence and your intended use is not permitted by statutory regulation or exceeds the permitted use, you will need to obtain permission directly from the copyright holder. To view a copy of this licence, visit http://creativecommons.org/licenses/by/4.0/. The Creative Commons Public Domain Dedication waiver (http://creativeco mmons.org/publicdomain/zero/1.0/) applies to the data made available in this article, unless otherwise stated in a credit line to the data. 
or closely-spaced pregnancies during the first twelve months following delivery but are not using any contraceptive method [6, 7].

Many women in SSA countries know the important role played by Family Planning (FP) in preventing unwanted pregnancies, but what they may not know is its role in planning and improving the lives and families of the users [8]. In developing countries, it was estimated in 2012 that 222 million women had an unmet need for FP [9]. Moreover, reducing the unmet need for FP in SSA and other developing countries would avert more than one million infant deaths and 54 million unwanted pregnancies which, if not prevented, would result in 21 million inadvertent births, seven million miscarriages, and 26 million abortions of which 15 million would be unsafe [9].

By preventing undesirable pregnancy, FP averts maternal and childhood deaths and helps a woman decide freely and conscientiously about her pregnancy spacing and parity [1]. Additionally, when the unmet contraceptive need is reduced, women's wellbeing, education and autonomy are improved, and the need for unsafe abortion is reduced [10]

Currently, the fertility rate in Africa stands at 4.7 children per woman, which is the highest in the world [11]. One in 26 adult women is at risk of maternal death in SSA due to poor reproductive health, compared to 1 in 7300 women in developed countries [8]. Providing postpartum women with access to FP would thus improve their reproductive health and save them from maternal deaths.

Data from seventeen developing countries have shown that the unmet need for PPFP has reached $88 \%$ in some SSA countries and that women in the postpartum period have more unmet needs for modern contraceptive methods than any other women $[12,13]$. This is likely to be associated with the lack of FP counselling during the antenatal and postnatal period, and negligence of the PPFP needs by national family planning programmes [14, 15]. It should be noted that four of the six countries with the highest unmet need for FP in the world are in SSA, namely the Democratic Republic of the Congo (DRC), Uganda, Nigeria, and Kenya [16].

Conversely, contraceptive uptake within a short time after the childbirth was found to increase contraceptive discontinuation, which consequently put postpartum women at higher risk of pregnancy. For example, in some countries in SSA, South Asia, Asia Pacific, and South America early users of modern contraceptives experienced higher pregnancy risks than non-users due to the discontinuation of the contraceptives around the same time they are at most need $[16,17]$. Among women who discontinue one modern contraceptive method due to its side-effects or other problems related to the method, only 13 percent switch to another method [18]. This would suggest that there is a need to understand these deep-rooted reasons for the lack of uptake of PPFP as these might go beyond the non-availability of modern contraceptives in health facilities or the economic situation of SSA countries. For this reason, the current review assessed both the factors associated with women's unmet need for PPFP and their reasons for not utilising contraceptives.

Although extensive research has been carried out on the unmet need for PPFP, no single review investigating both unmet need for PPFP and the reasons for non-use in SSA exists. Earlier reviews on FP omitted to study the unmet need in the postpartum period $[4,19]$. Other studies $[7,20]$ have also considered reasons for non-use of FP methods but focused neither on postpartum women nor SSA countries. Therefore, the focus of this review is unique which has aimed to address two questions about PPFP need in SSA: (a) investigate the unmet need for modern FP; (b) identify associated factors and reasons which lead women not to utilise modern FP in SSA.

\section{Methods}

Studies that met the inclusion criteria detailed below were included.

\section{Inclusion and exclusion criteria}

To be included, studies had to (i) examine and identify factors affecting the unmet need for modern FP, (ii) include modern contraceptive methods, (iii) to access current research in this area, published between January 2014 and December 2019 [21], (iv) report specific results only in SSA countries, (v) included only women in their twelve-month postpartum period, (vi) have accessible full-length articles, (vii) published in the English language, and (viii) were peer-reviewed and of any study design (qualitative, quantitative, or mixed methods) and the latter was decided due to the complexity of topic [22]. Exclusion criteria were the direct opposite of these inclusion criteria. Additionally, studies examining factors associated with only one modern contraceptive method were excluded.

\section{Search strategy}

The PICO framework [23-26] was author-adapted (PIO: Population: postpartum woman, Intervention: unmet need for modern FP methods and Factors as Outcomes) to formulate the research question. Though this framework helped formulate and hone the research question, this tool was only one contributing factor. The review followed the framework for reviews by Arksey and O'Malley [27] which is a standard approach for conducting scoping 
reviews, comprising five stages: identifying the research question, identifying relevant studies, study selection, charting the data and collating, summarising and reporting the results. PRISMA checklist [27, 28] was used, and a flow diagram (see Fig. 1) is presented to explain different phases of the article selection as described in the PRISMA guidelines [29].

To evaluate factors affecting the unmet need for PPFP in SSA and summarise evidence for practice [30], a literature review of recent studies was carried out. An initial pool of articles was built by searching several bibliographic databases in a UK-based University's Library e-resources: MEDLINE, Cochrane Review, PubMed, BMC Health Services Research, Elsevier's Science Direct and Web of Science. Additional articles were retrieved through hand-searching (e.g., visiting the organisation's websites) and reference mining (i.e., consulting reference list of relevant sources to explore other related literature [31, 32]. Furthermore, PROSPERO was searched for a broader range of results to check whether a similar review is registered [33]. To develop a more inclusive search, Google Scholar was searched; however, with a degree of prudence as it covers non-empirical, and often irrelevant, evidence.

The following combination of keywords and their synonyms was developed and applied in the search, population: postpartum women, postpartum, puerperium, postnatal, perinatal; Intervention: (a) family planning, birth spacing, contraceptive method, birth control, contraception, birth limiting; (b) unmet need, gap, non-use, unmet trend; outcome: factor, challenge, barrier, predictor, cause, reason. Wildcard characters were used to

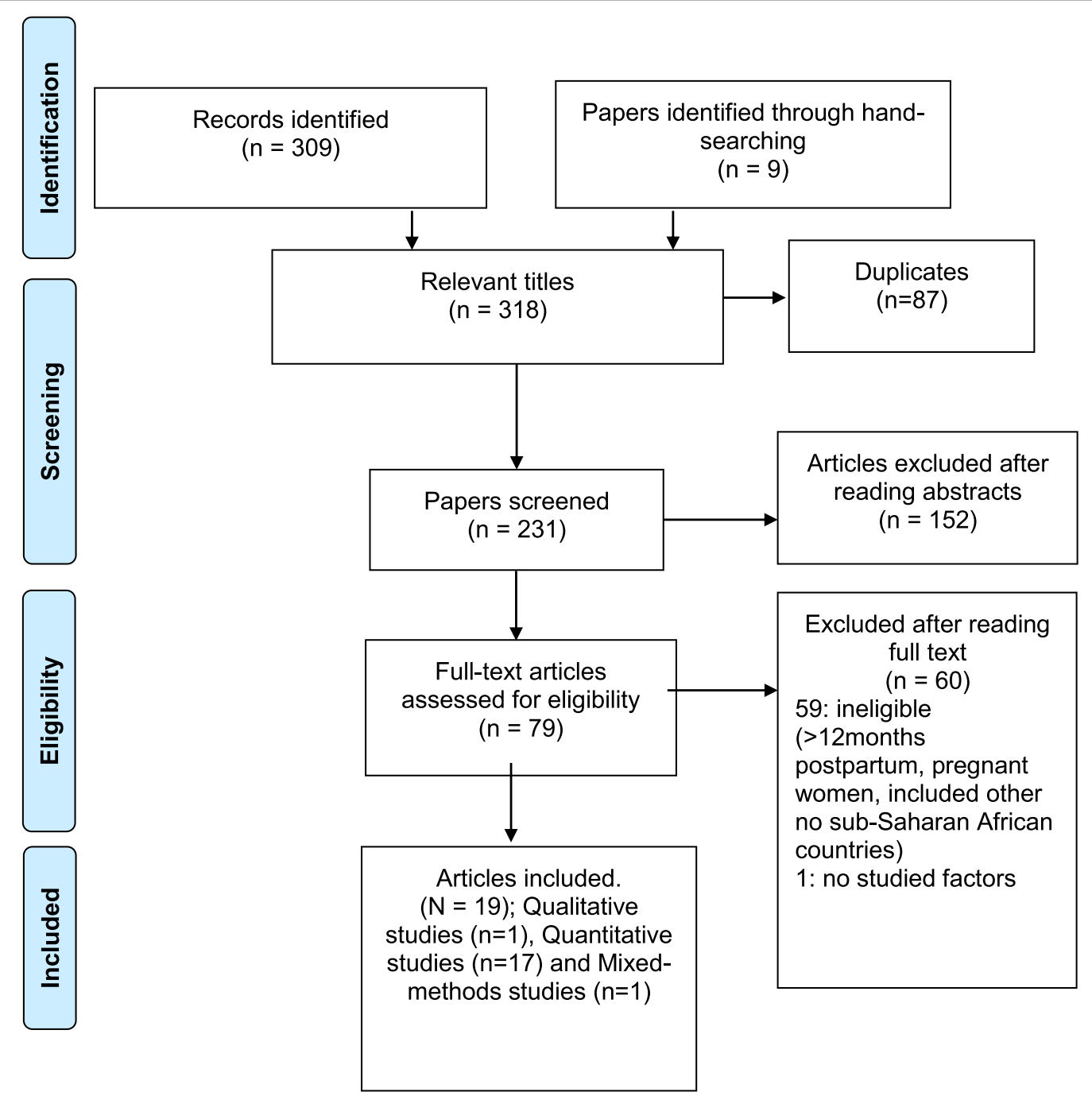

Fig. 1 PRISMA flow diagram 
include plurals or for words that may have more than one spelling [34].

For each bibliographic database, appropriate syntaxes with field codes, Boolean operators, and parentheses were used. It is commonly known that each database follows a set of rules and symbols to operate effectively, but at the same time, that some syntax rules are similar for most databases [35]. Therefore, appropriate syntaxes that take into account all similarities and differences were formed and faithfully employed. However, due to the paucity of studies on this topic in SSA [5], the use of Boolean "AND" alone was reduced when searching for articles to include in this study as it could have highly limited the number of retrieved papers, with the risk of excluding eligible studies [36]. As an alternative, the specifier "OR" was added to find as many potential articles as possible on postpartum FP in SSA and based on the eligibility, the list was afterwards narrowed down.

\section{Screening}

Included studied were first assessed against their title and abstracts and the full texts were afterwards screened [34, 36]. To prevent any eventual location, researcher, and publication bias [37], papers that met the eligibility criteria were identified and then independently reviewed by two reviewers. Any disagreements were discussed in detail between all three authors. Duplicates were automatically removed and where relevant, manually removed [34].

\section{Data extraction}

Nineteen studies were assessed and confirmed by two different reviewers. The following information was extracted from the included papers: authors; country and setting, sample, recruitment period, methods and summary points, and key findings. The summary points and key findings included study highlights, factors at the multivariate level, and reasons for not using PPFP.

\section{Quality appraisal}

This review primarily aimed to collect available evidence that leads postpartum women not to use modern contraception and to provide a description of the current state of knowledge on the topic. For the quality appraisal of all the 19 studies, an auto-adapted checklist from CASP qualitative checklist [38], Moule et al. [39], and a checklist used in similar systematic reviews [40] was made and used as shown in Appendix 1 (summary of qualityassessment criteria).

Each element of quality-assessment was scored on a binary level, with 1 implying that the criteria were met and 0 that it was not. Each study was assessed based on the following nine criteria: research aim; defined demand; research design; sampling/recruitment; data collection; methods; data analysis; ethical consideration; reliability. A study was considered high-quality if the sum of met criteria is six or higher and low-quality if its score is five or lower. However, due to the small number of eligible studies, no study was excluded based on quality.

Ethical approval for a literature review is not required [32], it was not thus sought.

\section{Results}

The search of databases and hand-searching provided a total of 318 papers, after adjusting for duplicates, 231 papers remained. After reading abstracts, 152 papers were excluded. The full text of 79 articles were assessed for the inclusion criteria, and nineteen studies met those criteria (see Fig. 1). Of these, eleven were conducted in Ethiopia [41-50, 59], three in Nigeria [51-53], two in Malawi $[54,55]$, two in Kenya $[56,57]$ and, one in Uganda [58].

Seventeen studies used quantitative methods, one mixed-methods, and one used a qualitative approach (Table 1). Of the studies using quantitative/mixed-methods, only one was prospective cohort research [51], the remainder followed a cross-sectional design (see Table 1 ). Twelve studies (63.2\%) recruited participants from the community-based settings and seven (36.8\%) from health institutions. Most studies (63.2\%) were published between 2018 and 2019. It should be noted that expanding the publication period for studies on unmet need for PPFP up to 10 years did not increase the numbers of relevant studies included.

The studies by Abraha 2017 [42] and 2018 [43] were conducted on the same sample; however, the authors have reported different results in the two published papers. Therefore, we decided to keep both papers in this review. Table 1 shows the characteristics of the included studies in the review.

The main findings of the included studies are presented in Table 2 and whether stated, also show the main reasons for not using the PPFP (10 studies in total). Highlights of the included studies indicate that many women did not visit the postnatal care services (PNC) and that the need for PPFP services as stated in most of the studies (Table 2).

Overall, this review found that generally factors associated with unmet need for PPFP (Tables 2 and 3) can be grouped in three levels as discussed below.

\section{Factors influencing the unmet need for PPFP at an individual level}

Women's education was a major factor contributing to their unmet need for PPFP as revealed in seven studies $[42,47,49,53,54,56,58]$. Other studies showed that the 
Table 1 Characteristics of the included studies

\begin{tabular}{|c|c|c|c|c|c|}
\hline Authors & $\begin{array}{l}\text { Country and state/ } \\
\text { region }\end{array}$ & Setting & Recruitment period & Type of study/method & Sample size \\
\hline Abera et al. 2015 [41] & Ethiopia, Gondar & Community-based & August 2013 & $\begin{array}{l}\text { Cross-sectional/quan- } \\
\text { titative }\end{array}$ & $N=703$ \\
\hline Abraha et al. 2017 [42] & Ethiopia, Aksum & Community-based & March-April, 2015 & $\begin{array}{l}\text { Cross-sectional/quan- } \\
\text { titative }\end{array}$ & $\begin{array}{c}N=590(\mathrm{~N} \text { expected } \\
[\mathrm{NE}]=601)\end{array}$ \\
\hline Abraha et al. 2018 [43] & Ethiopia, Aksum & Community-based & March-April 2015 & $\begin{array}{l}\text { Cross-sectional/ quan- } \\
\text { titative }\end{array}$ & $N=590(N E=604)$ \\
\hline Achwoka et al. 2018 [56] & Kenya & $\begin{array}{l}\text { Nationally representa- } \\
\text { tive }\end{array}$ & $\begin{array}{l}2013 \text { (month not speci- } \\
\text { fied) }\end{array}$ & $\begin{array}{l}\text { National cross-sec- } \\
\text { tional/quantitative }\end{array}$ & $N=955(N E=1012)$ \\
\hline $\begin{array}{l}\text { Gebremedhin et al. } \\
2018 \text { [44] }\end{array}$ & Ethiopia, Addis Ababa & Community-based & May-June 2015 & $\begin{array}{l}\text { Cross-sectional/quan- } \\
\text { titative }\end{array}$ & $\mathrm{N}=803(\mathrm{NE}=849)$ \\
\hline Dona et al. 2018 [45] & Ethiopia, Aroressa & Community-based & March-April, 2017 & $\begin{array}{l}\text { Cross sectional/quan- } \\
\text { titative }\end{array}$ & $N=684(\mathrm{NE}=695)$ \\
\hline Berta et al. 2018[46] & Ethiopia, Gondar & Healthcare facility & March-April 2015 & $\begin{array}{l}\text { Cross-sectional/quan- } \\
\text { titative }\end{array}$ & $N=404$ \\
\hline Bwazi et al. 2014 [54] & Malawi, Ntchisi & Healthcare facility & July 2011 & $\begin{array}{l}\text { Cross-sectional/quan- } \\
\text { titative }\end{array}$ & $N=383$ \\
\hline Thindwa et al. 2019[55] & Malawi & $\begin{array}{l}\text { nationally representa- } \\
\text { tive (nested) }\end{array}$ & May 2015-May 2016 & $\begin{array}{l}\text { Cross-sectional/quan- } \\
\text { titative }\end{array}$ & $N=578$ \\
\hline Chinaeke. 2019 [51] & $\begin{array}{l}\text { Nigeria (the Federal } \\
\text { Capital Territory and } \\
\text { Nasarawa state) }\end{array}$ & Healthcare facility & $\begin{array}{l}\text { April 2014-September } \\
2015\end{array}$ & $\begin{array}{l}\text { Prospective cohort } \\
\text { study/quantitative }\end{array}$ & $\mathrm{N}=399(\mathrm{NE}=497)$ \\
\hline $\begin{array}{l}\text { Embafrash and Mekon- } \\
\text { nen } 2019 \text { [59] }\end{array}$ & Ethiopia, Tahtay-Koraro & Healthcare facility & February-March 2014 & $\begin{array}{l}\text { Cross-sectional/mixed } \\
\text { methods }\end{array}$ & $N=409(\mathrm{NE}=422)$ \\
\hline Idowu et al. 2015 [52] & Nigeria, Ogbomoso & Healthcare facility & $\begin{array}{l}\text { Three months, year not } \\
\text { specified }\end{array}$ & $\begin{array}{l}\text { Cross-sectional/ quan- } \\
\text { titative }\end{array}$ & $N=444$ \\
\hline Iliyasu et al. 2018 [53] & Nigeria, Kano & Healthcare facility & January-February 2015 & $\begin{array}{l}\text { Cross-sectional/ quan- } \\
\text { titative }\end{array}$ & $N=317(N E=371)$ \\
\hline Keesara et al. 2018 [57] & Kenya, Nairobi & Healthcare facility & $\begin{array}{l}\text { December 2013-April } \\
2014\end{array}$ & $\begin{array}{l}\text { Cross-sectional/quali- } \\
\text { tative }\end{array}$ & $N=91$ \\
\hline Tegegn et al. 2017 [47] & Ethiopia, Dessie & Community-based & December 2014 & $\begin{array}{l}\text { Cross-sectional/quan- } \\
\text { titative }\end{array}$ & $N=383$ \\
\hline $\begin{array}{l}\text { Mengesha et al. } 2015 \\
\text { [48] }\end{array}$ & Ethiopia, Dabat & Community-based & January 2013 & $\begin{array}{l}\text { Cross-sectional/ quan- } \\
\text { titative }\end{array}$ & $N=899(\mathrm{NE}=816)$ \\
\hline Gejo et al. 2019 [49] & Ethiopia, Hossana & Healthcare facility & June-July 2018 & $\begin{array}{l}\text { Cross-sectional/ quan- } \\
\text { titative }\end{array}$ & $N=368$ \\
\hline Sileo et al. 2015 [58] & Uganda, Butambala & Healthcare facility & $\begin{array}{l}\text { 2010, month no speci- } \\
\text { fied }\end{array}$ & $\begin{array}{l}\text { Cross-sectional/ quan- } \\
\text { titative }\end{array}$ & $N=258(N E=301)$ \\
\hline Abraha et al. 2018 [50] & $\begin{array}{l}\text { Ethiopia (Tanquae- } \\
\text { Abrgelle, Adwa, } \\
\text { Tahtay-Maychew and } \\
\text { Laelay-Maychew) }\end{array}$ & Community-based & March-April 2017 & $\begin{array}{l}\text { Cross-sectional/ quan- } \\
\text { titative }\end{array}$ & $N=1109$ \\
\hline
\end{tabular}

NE number expected

association was found at the bivariate and not at multivariate analysis level $[41,45,48,50,52,59]$. In contrast to the studies mentioned above, women's education was not a determinant of unmet contraceptive need in two studies $[44,51]$.

Of the thirteen studies that explored women's age as a factor of unmet need for PPFP, three studies found it statistically significant at multivariate regression level [41, $55,56]$ and five studies at the bivariate level $[47,48,53$, $54,59]$. Additionally, for some studies, the unmet need for FP was lower in younger postpartum women $[41,56]$ as opposed to [55] who concluded the unmet need to be higher in younger postpartum women.

Women's parity was found to be a factor influencing the unmet need for PPFP in two of the included studies. Bwazi and colleagues [54] concluded the wanted number of children statistically affects the unmet contraceptive need, whilst Thindwa et al. [55] showed that primiparous women had a greater unmet need for contraception than women with three or more parities. The number of living 


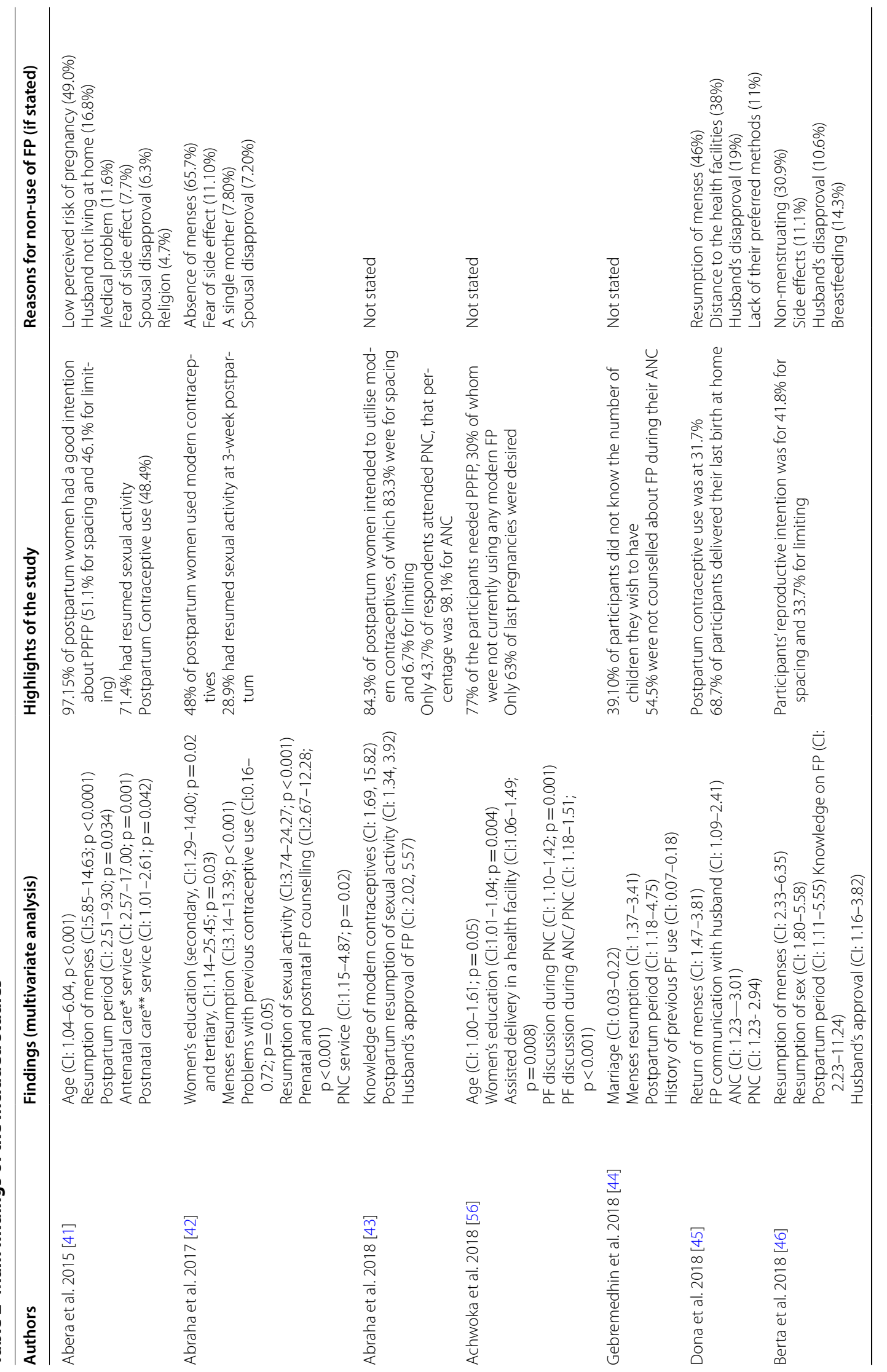




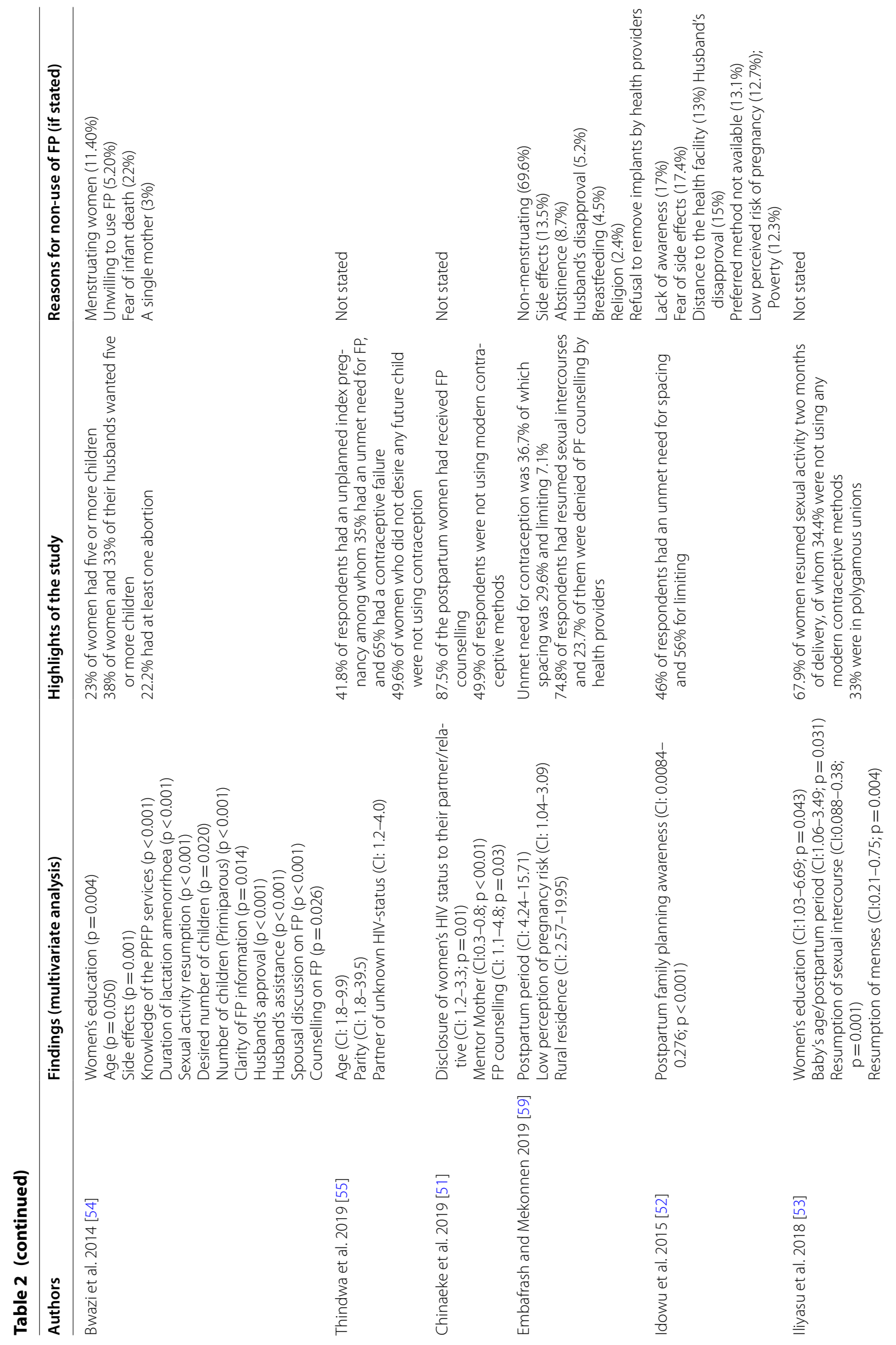




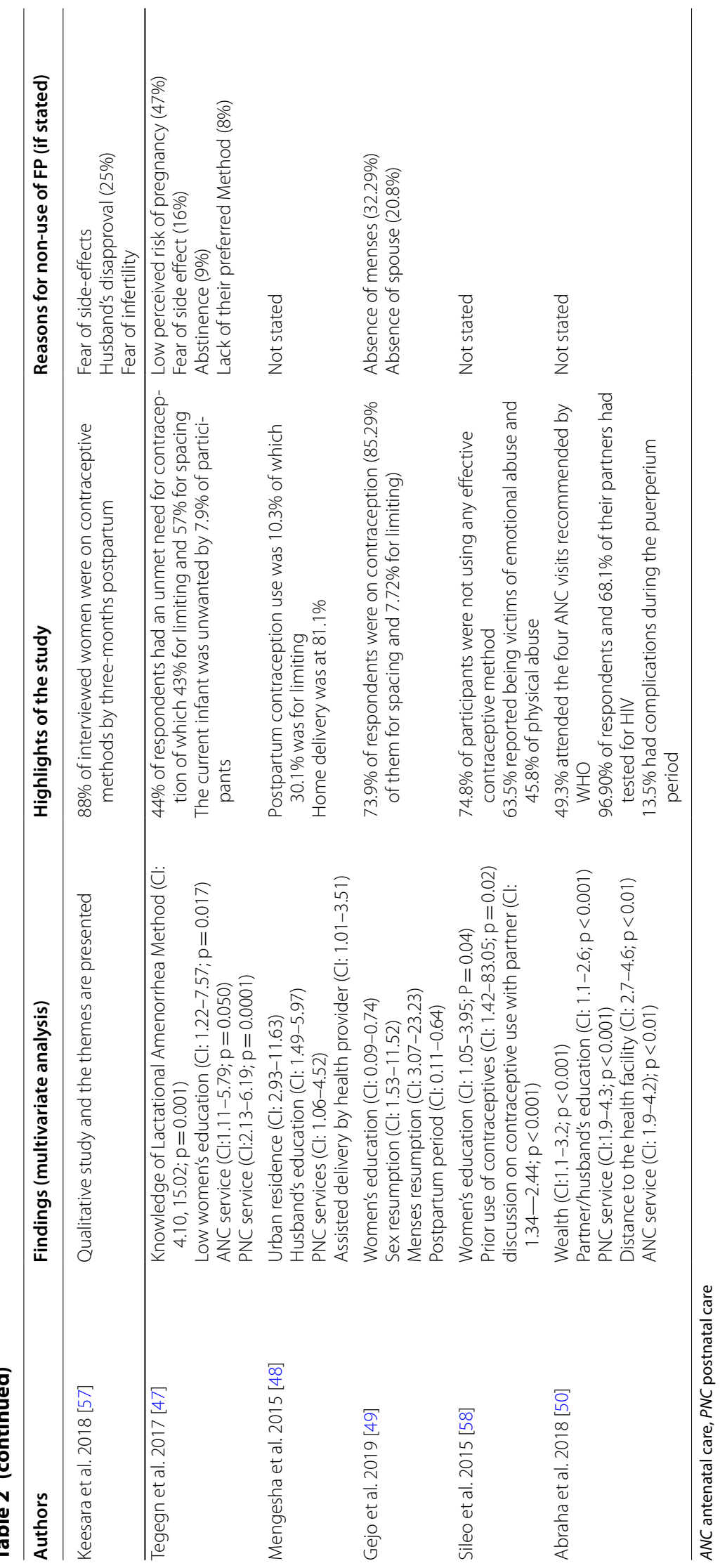


Table 3 Major factors affecting the use of PPFP methods in SSA countries at three levels*

\begin{tabular}{|c|c|c|}
\hline Main themes & Number of Studies & Findings (multivariate analysis) \\
\hline \multicolumn{3}{|l|}{ Individual level } \\
\hline Women's education (6 studies) & 7 studies & $\begin{array}{l}\text { Decreased effect: Abraha et al. } 2017 \text { [42]; Achwoka et al. } 2018 \text { [56]; Bwazi et al. } 2014 \text { [54]; } \\
\text { Iliyasu et al. } 2018 \text { [53]; Tegen et al. } 2017 \text { [47]; Gejo et al. } 2019 \text { [49]; Sileo et al. } 2015 \text { [58] }\end{array}$ \\
\hline Women's age & 4 studies & $\begin{array}{l}\text { Increased effect: Abera et al. } 2015 \text { [41]; Achwoka et al. } 2018 \text { [56]; Bwazi et al. } 2014 \text { [54]; } \\
\text { Thindwa et al. 2019[55] }\end{array}$ \\
\hline Women's parity & 2 studies & Increased effect: Thindwa et al. 2019[55]; Bwazi et al. 2014 [54] \\
\hline Resumption of menses & 7 studies & $\begin{array}{l}\text { Decreased effect: Abera et al., } 2015 \text { [41]; Abraha et al., } 2018 \text { [43]; Gebremedhin et al., } 2018 \\
\text { [44]; Dona et al., } 2018 \text { [45]; Berta et al., } 2018 \text { [46]; Gejo et al., } 2019 \text { [49]; Iliyasu et al., } 2018 \\
\text { [53] }\end{array}$ \\
\hline Resumption of sexual activity & 6 studies & $\begin{array}{l}\text { Decreased effect: Abraha et al., } 2017 \text { [42]; Abraha et al., } 2018 \text { [43]; Berta et al., } 2018 \text { [46]; } \\
\text { Gejo et al., } 2019 \text { [49]; Iliyasu et al., } 2018 \text { [53]; Bwazi et al., } 2014 \text { [54] }\end{array}$ \\
\hline Knowledge of FP methods & 5 studies & $\begin{array}{l}\text { Increased effect: Abraha et al., } 2018 \text { [43]; Berta et al., } 2018 \text { [46]; Tegegn et al., } 2017 \text { [47]; } \\
\text { Idowu et al., } 2015 \text { [52]; Bwazi et al., } 2014 \text { [54] }\end{array}$ \\
\hline \multicolumn{3}{|l|}{ Household level } \\
\hline Husband's approval & 3 studies & Increased effect: Abraha et al., 2018 [43]; Berta et al., 2018 [46]; Bwazi et al., 2014 [54] \\
\hline Husband's education & 2 studies & Increased effect: Mengesha et al., 2015 [48]; Abraha et al., 2018 [50] \\
\hline FP discussion with husband/partners, & 3 studies & Increased effect: Dona et al., 2018 [45]; Bwazi et al., 2014 [54]; Sileo et al., 2015 [58]; \\
\hline \multicolumn{3}{|l|}{ Health care facility level } \\
\hline ANC & 5 studies & $\begin{array}{l}\text { Decreased effect: Abera et al., } 2015 \text { [41]; Tegegn et al., } 2017 \text { [47]; Dona et al., } 2018 \text { [45]; } \\
\text { Abraha et al., } 2018 \text { [50]; Achwoka et al., } 2018 \text { [56] }\end{array}$ \\
\hline PNC & 7 studies & $\begin{array}{l}\text { Increased effect: Abera et al., } 2015 \text { [41]; Dona et al., } 2018 \text { [45]; Tegegn et al., 2017[47]; } \\
\text { Abraha et al., } 2018 \text { [50]; Achwoka et al., } 2018 \text { [56]; Abraha et al., } 2017 \text { [42]; Mengesha } \\
\text { et al., } 2015 \text { [48] }\end{array}$ \\
\hline
\end{tabular}

children was not significant at multivariate regression analysis, but the significance was, however, found in five studies at the bivariate level $[41,42,48,53,56]$.

Though breastfeeding was given as one of the reasons not to use PPFP $[46,47,59]$, only one study found a significant association between the duration of lactation amenorrhoea and the PPFP services [54]. The resumption of menses was associated with PPFP in seven studies [41, $42,44-46,49,53]$.

Several other factors affecting PPFP in SSA were examined at this level. The resumption of sexual activity was discussed in six studies and was found to positively influence the uptake of PPFP in all $[42,43,46,49,53,54]$. The length of postpartum period, i.e. the age of the infant, influenced the utilisation of PPFP in six studies at multivariate level $[41,44,46,49,53,59]$. The knowledge that the respondents had of FP was examined in ten studies and was found to be negatively associated with unmet need in five studies [43, 46, 47, 52, 54]. Furthermore, prior use of contraceptives, low perceived risk of pregnancy, and women's wealth/income were also determinants of the PPFP (Table1).

\section{Factors influencing the unmet need for PPFP at the household level}

The husband's approval was examined in four studies and was a significant factor of unmet need for FP in three of the studies [43, 46, 54]. Other associations with unmet need for PPFP were examined in relatively few studies and found statically significant, which included husband's education $[48,50]$, FP discussion with husbands/partners $[45,54,58]$, husband's assistance [54], disclosure of HIV status to husband/partner and mentor mother [51].

\section{Factors influencing the unmet need for contraception at health care facility level}

Among the eight studies that evaluated antenatal care (ANC) services, five found a strong association with the unmet contraceptive need [41, 45, 47, 50, 56]. Those five studies along with two others $[42,48]$ revealed postnatal care (PNC) services to be determinants of PPFP uptake. The FP counselling provided by health care providers during both ANC and PNC services was positively associated with the uptake of PPFP in four studies out of five that examined this factor $[42,51,54,56]$. Additionally, though the association was not established with an adjusted odds ratio, crude odds ratio concluded an association between ANC and the unmet contraceptive need in three more studies [42, 48, 49].

Reasons for not utilising PPFP were raised in ten studies. The major reasons reported by most participants were 'no return of menses' stated in six studies, the 'fear of side effects' mentioned in eight studies, 'husband's disapproval' stated in six studies, 'abstinence' and 'low 
perceived risk of pregnancy' respectively mentioned in three and two studies, 'lack of preferable contraceptive method' stated in three studies, 'fear of infertility' stated in two studies. Other reasons raised by few respondents (less than 4\%), sometimes examined in only one study, as showed in Table 2, which included 'poverty', 'health provider incompetency', 'unwilling to use family planning, and 'fear of death'.

It should be stressed that religion was mentioned in only two studies by less than $5 \%$ of the study participants as one of the reasons they were not on modern contraceptive methods [41, 59], which might be explained by the fact that, as suggested by [60], religious women can still prefer to use modern contraceptives despite religious opposition.

A conceptual diagram was developed presenting a theoretical connection between the individual, household, and health facility characteristics and unmet needs for PPFP in women in SSA countries (Fig. 2).

\section{Discussion}

This is the first study to systematically review both the factors influencing the unmet need for PPFP and the reasons raised by postpartum women on their utilisation of modern contraceptive methods. The results in this review are based on nineteen original studies, published within the last five years which studied determinants of unmet need for PPFP and reasons that lead women in the postpartum period not to use modern contraceptives in SSA. The reviewed articles provided evidence for the unmet contraceptive needs and this review compared and highlighted all the factors and predictors reported in the studies. Reasons for not using contraceptive methods put forward by the postpartum women were mostly different from statistically significant factors affecting the use of contraception.

The low education level of either women or their husbands/partners was found to be a major factor of unmet need for FP in many studies. Evidence suggests that women's education can contribute to the improvement of contraceptive uptake during the postpartum period and therefore reduce the unmet PPFP need [61-63]. A husbands' education was a key factor in the promotion of contraceptive use [64]. This might be explained by the fact that the educational status of either partner plays a crucial role in empowering both spouses, reducing gender inequality, and promoting discussion and support within a household. Hence, to be able to increase their utilisation of contraception and thus reduce the unmet need for PPFP, the education of both women and men need to be improved and, health providers should focus more on women with less education when they visit the $\mathrm{ANC}$ and PNC services.

The age of women, either young or old, depending on the type of contraceptives, can affect the PPFP as found in this literature review. This converges with the findings of a study conducted in the USA (United States of America) which showed that being younger (age 21-25)

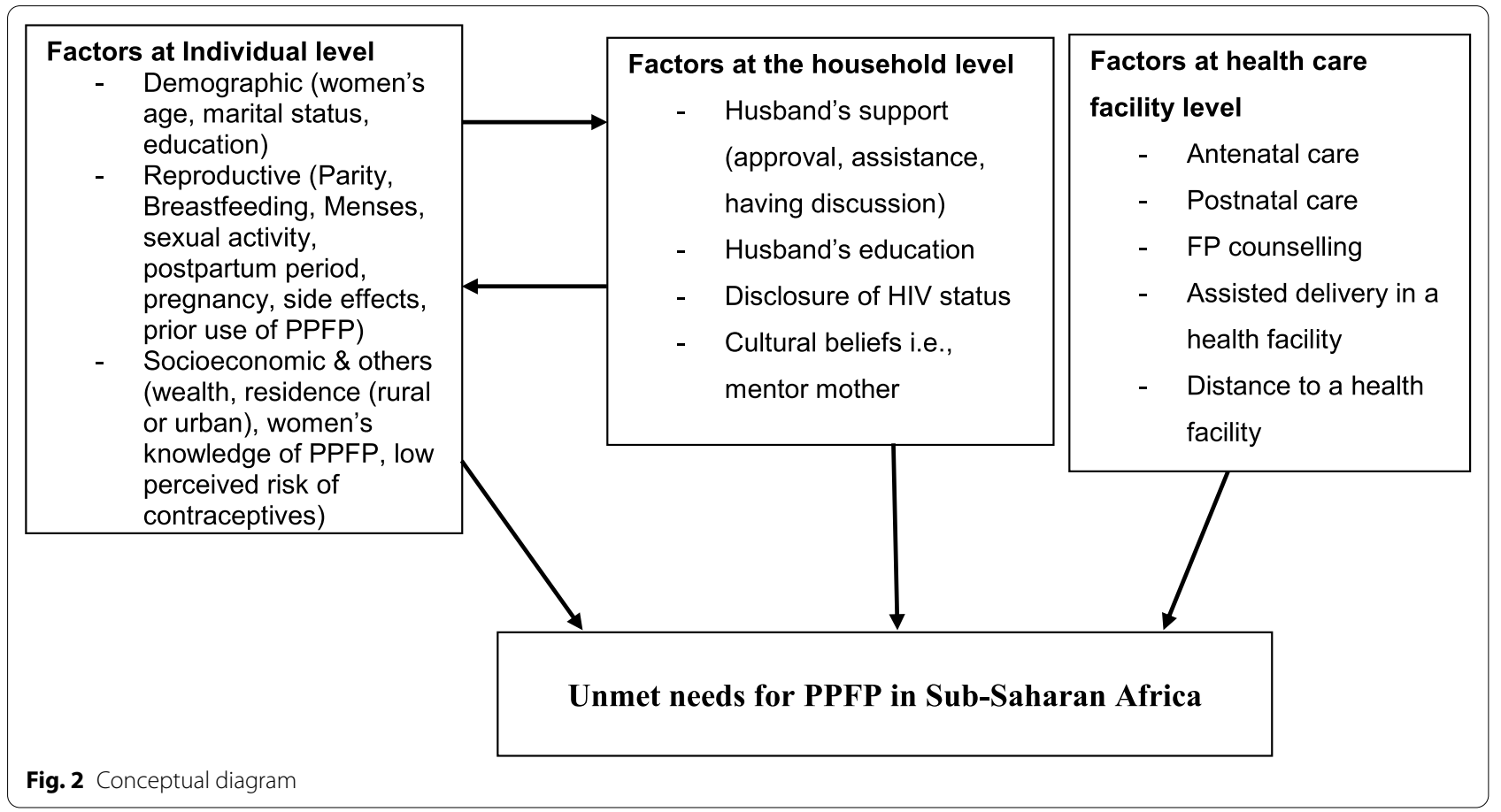


was a risk factor for limited contraceptive methods [65]. This might be because, as suggested by young postpartum women, they face more problems accessing PPFP programmes than older ones in SSA. It could be that contraceptive use can be higher in younger women because they are more sexually active, thus tend to utilise more contraceptive methods than their counterparts [66].

The resumption of menses was also associated with the contraceptive use and, 'breastfeeding' and 'no return of menses' were among the reasons for not using contraceptives in the included studies. Data from seventeen countries showed that the resumption of menses was a determinant of unmet need for PPFP [67] and another multicentre study in Kenya, Peru, the Dominican Republic and Indonesia found an association between breastfeeding and unmet need for PPFP [68]. The possible reason for the association might not only be that most women in Africa assume being at risk of pregnancy when their menses return but also that, healthcare providers state to women that menstruation is a sign of fecundity and hence, advise women to seek for FP services after the resumption of their periods [69]. Additionally, as the majority of women in SSA breastfeed for a relatively extended period [70], they might be reluctant to initiate any modern contraceptive method soon after birth believing there is no risk of pregnancy. Studies have shown that the extended period of breastfeeding for up to two years in SSA can substantially lengthen the period of amenorrhea and that the sexual abstinence can be respected for an extended period after a birth influence, which should generally reduce the unmet need for PPFP [3]. However, the return of fecundity is often unpredictable among women $[71,72]$. The longer the postpartum period, the higher the likelihood of ovulation becomes, and ovulation usually precedes the first return of menses [73]. Therefore, adequate knowledge about pregnancy risk should be provided to both women prior to the return of their menstruation and the health providers as part of their continuous training because, as documented, FP counselling is overlooked by some health providers during ANC and PNC [72].

Women in the postpartum who knew about FP were more likely to utilize PPFP than their counterparts. This result was in line with other studies conducted in Africa $[74,75]$. This tells us that women's exposure to FP information can increase demand for FP services and that sub-Saharan countries need to prioritise raising awareness on PPFP. This can cause positive behavioural change [76], addressing unmet FP needs, and help prevent abuse and unsafe abortion [77, 78]. While very little is known in Africa about the latter, the few existing studies suggest high rates of unsafe abortion and that improving FP services would be the best solution to prevent abortion
[78, 79], corroborating therefore Bwazi et al. [54] who revealed a high rate of abortion among their respondents.

Findings from this review have also highlighted the influence of partners in using PPFP. The role of spouses' disapproval and discussing using modern contraceptives with male partners shows how deep the inequity is in the household in terms of decision making. In most, if not all, SSA countries, the husband generally makes all important decisions for the family, including reproductive ones [80]. Sometimes secret contraceptive use is adopted where a woman in a family faces opposition and barriers to FP utilisation. However, FP users mostly respect their husbands' decisions. This highlights the need for husbands or male partners to be involved in maternal health services and, most importantly, encouraged to accompany their wives/partners to ANC and PNC services as recommended in some Asian countries [81].

ANC and PNC services and 'FP counselling' provided by health care providers have been identified as major contributing factors to the unmet need for PPFP methods in the majority of the studies included in this review. Women who did not receive ANC and/or PNC were significantly less likely to adopt any modern contraceptive during their postpartum period. Though 'the FP counselling' to pregnant women was not statistically significant in influencing the unmet need for PPFP in studies conducted in Tanzania and Uganda [82, 83], the findings of this review were similar to those reported in order parts of the world, including in SSA [84, 85], Mexico [86] and the USA [60]. Previous studies in SSA have shown that ANC and PNC services are often limited $[87,88]$ and that most mothers who deliver at home do not visit health facilities afterwards to receive PNC [48]. The integration of FP services into maternal and other child health services such as ANC, PNC, and immunisation services, therefore, should be improved. Our review suggests programmes to reach women who delivered at home should be implemented in all those areas where the rate of home delivery is high. In the majority of studies, postpartum women provided substantive reasons as to why they were not using any modern contraceptive method. Similarly, the same reasons have been reported in many other lowand middle-income countries [16,89].

\section{Strengths and limitations}

This review included recent studies assessing up-todate factors and findings that will attract researchers in the field to orient their future research towards PPFP in SSA. Although the selection of studies for this literature was systematic, it is possible that some relevant publications were missed, such as studies published in non-English journals. The included studies were dominated by cross-sectional design which can generally 
show an association rather than causality and, there were a limited number of countries. Consequently, this might have reduced the generalisability of the findings on the unmet need for PPFP to the entire SSA. However, this review will be of interest to those tasked with the improvement of FP programmes; and health policymakers in Africa. A concern about the interpretation of results was the geographic distribution of the studies, as eligible studies came from only five out of 48 SSA countries [90]. The majority of studies focused on individual-level factors and presented a lack of contextual factors related to the healthcare system. Though reasons for not using modern contraceptives were given in most studies, more qualitative studies complement our findings for the reasons raised by postpartum women. However, the outcomes of this review remain relevant for the whole of Sub-Saharan Africa because of similarities in economic and socio-cultural circumstances and health systems across countries [91, 92].

\section{Conclusions}

This review uncovered several plausible and significant factors that highlight the unmet needs for FP amongst of postpartum women in SSA. Reasons for the limited utilisation of modern contraceptives among women were discussed, and the significant determinants are now foregrounded. There is a clear knowledge gap, and the lack of awareness regarding the use of modern FP methods and their effectiveness during the postpartum period in SSA women has been identified. Further research is needed into the impact on the use of FP by women; intimate partner violence; and the association between abortion and the unmet need for modern contraceptives in SSA. Effective interventions and programmes that address the PPFP needs and managing their side effects are urgently required to reduce the unmet need for modern FP methods for postpartum women in SSA.

\section{Abbreviations}

PPFP: Postpartum family planning; ANC: Antenatal care; PNC: Postnatal care; SSA: Sub-Sahara (n); FP: Family planning; UN: United Nations; USA: United States of America.

\section{Authors' contributions}

JG conceived the idea and PR and MV helped with the design of the review. JG conducted the literature searches, screening of the records, and extracted the data. PR and MV appraised the quality of evidence. JG wrote the first draft. All authors were responsible for revising the manuscript critically for important intellectual content. All authors read and approved the final manuscript.

\section{Funding}

Not applicable.

\section{Availability of data and materials Not applicable.}

Ethics approval and consent to participate Not applicable.

Consent for publication

Not applicable.

\section{Competing interests}

The authors declare that they have no competing interests.

\section{Author details}

${ }_{1}^{1}$ Martin Luther King University, Bujumbura, Burundi. ${ }^{2}$ Peninsula Medical School, Faculty of Health, University of Plymouth, Plymouth, UK. ${ }^{3}$ Faculty of Health and Social Sciences, Bournemouth University, Bournemouth Gateway Building, 10 St Paul's Ln, BH8 8AJ Bournemouth, UK. 
Gahungu et al. Reprod Health

(2021) $18: 35$

Page 13 of 15

Appendix 1. Critical appraisal of the included studies

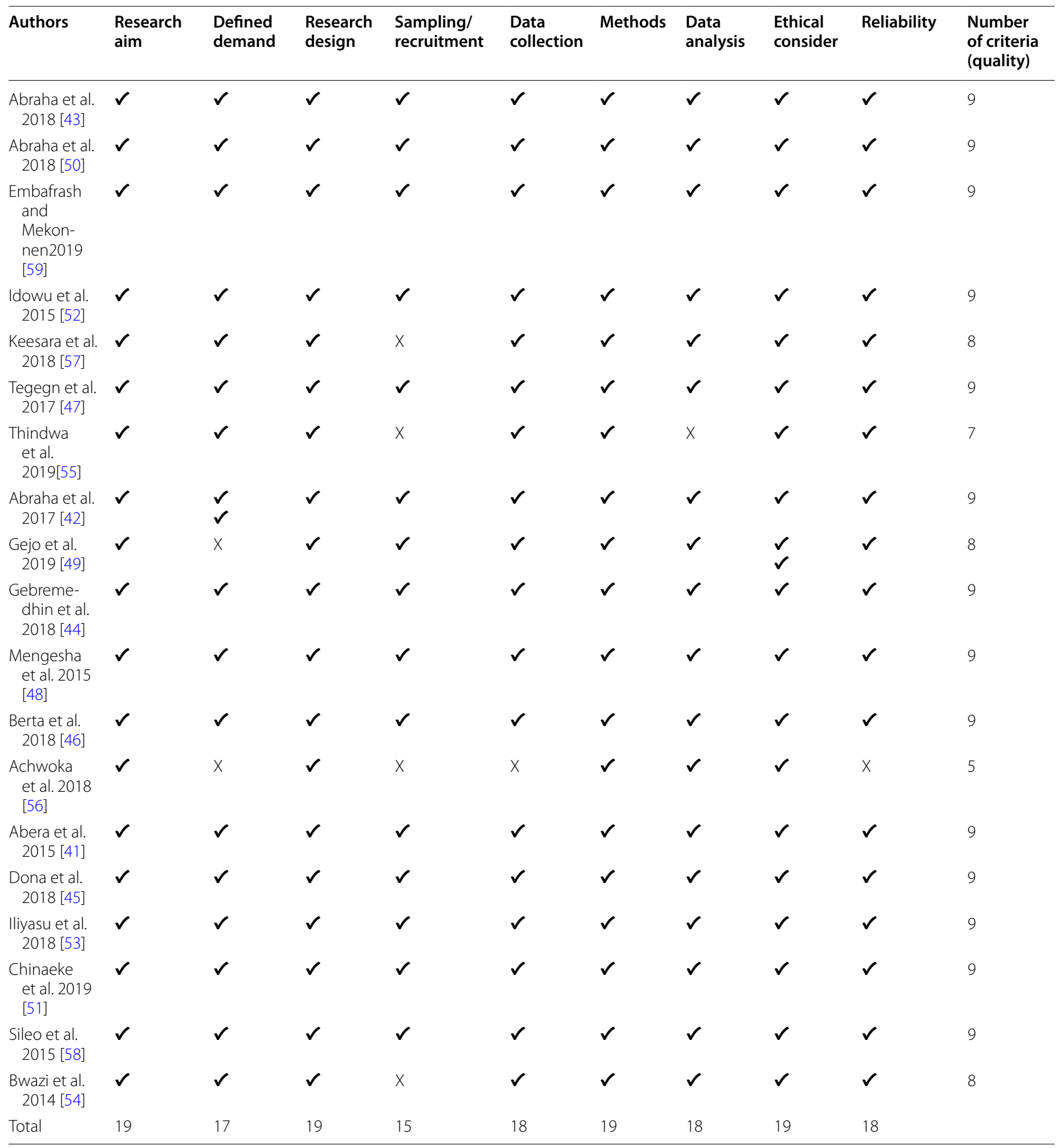

Received: 2 January 2020 Accepted: 27 January 2021

Published online: 10 February 2021 


\section{References}

1. United Nations, Department of Economic and Social Affairs. World Family Planning; New York: UN. 2017.

2. RamaRao S, Ishaku S, Liambila W, Mane B. Enhancing contraceptive choice for postpartum women in sub-Saharan Africa with the progesterone vaginal ring: a review of the evidence. Open Access J Contracept. 2015;6:117-23.

3. Rossier C, Hellen J. Traditional birthspacing practices and uptake of family planning during the postpartum period in Ouagadougou: qualitative results. Int Perspect Sex Reprod Health. 2014:40(2):87-94.

4. Wulifan JK, Brenner S, Jahn A, De Allegri M. A scoping review on determinants of unmet need for family planning among women of reproductive age in low and middle income countries. BMC Women's Health. 2015;16(1):2

5. Cleland J, Shah $1 \mathrm{H}$, Daniele M. Interventions to improve postpartum family planning in low-and middle-income countries: program implications and research priorities. Stud Fam Plan. 2015;46(4):423-41.

6. United Nations. World contraceptive use. Geneva: United Nations; 2014.

7. Sedgh G, Ashford LS, Hussain R. Unmet need for contraception in developing countries: examining women's reasons for not using a method. New York: Guttmacher Institute; 2016.

8. United Nations, Statement submitted by International Planned Parenthood Federation (IPPF), a non-governmental organization in consultative status with the Economic and Social Council; E/CN.9/2010/NGO/1; United Nations: Geneva; 2010.

9. Singh S, Darroch J E. Adding it up: costs and benefits of contraceptive services. Guttmacher Institute and UNFPA. 2012.

10. Lane C, Joof YM, Hassan AA, Pryor S. Promoting healthy timing and spacing of pregnancy with young married women in Northern Nigeria: a short report. Afr J Reprod Health. 2012;16(2):263-9.

11. United Nations. World fertility patterns. 2015. https://www.un.org/en/deve opment/desa/population/publications/pdf/fertility/world-fertility-patte rns-2015.pdf. Accessed 1 Jan 2019.

12. Borda M, Winfrey W. Postpartum fertility and contraception: an analysis of findings from 17 countries. Baltimore: JHPIEGO; 2010.

13. Adebowale SA, Palamuleni ME. Determinants of unmet need for modern contraception and reasons for non-use among married women in rural areas of Burkina Faso. Afr Popul Stud. 2014:28(1):499-514.

14. Pasha O, Goudar SS, Patel A, Garces A, Esamai F, Chomba E, Moore JL, Kodkany BS, Saleem S, Derman RJ, et al. Postpartum contraceptive use and unmet need for family planning in five low-income countries. Reprod Health. 2015:12(Suppl 2):S11.

15. Wilopo SA, Setyawan A, Pinandari AW, Prihyugiarto T, Juliaan F, Magnani RJ. Levels, trends and correlates of unmet need for family planning among postpartum women in Indonesia: 2007-2015. BMC Women's Health. 2017;17:120.

16. Cleland J, Shah $\Vdash H$, Benova L. A fresh look at the level of unmet need for family planning in the postpartum period, its causes and program implications. Int Perspect Sex Reprod Health. 2015;41(3):155-62.

17. Ngianga-Bakwin K, Stones RW. Birth intervals and injectable contraception in sub-Saharan Africa. Contraception. 2005:71(5):353-6.

18. Ali MM, Cleland JG, Shah IH, World Health Organization. Causes and consequences of contraceptive discontinuation: evidence from 60 demographic and health surveys. Geneva: WHO; 2012.

19. Haider TL, Sharma M. Barriers to family planning and contraception uptake in sub-Saharan Africa: a systematic review. Int Q Comm Health Educ. 2013;33(4):403-13.

20. Sedgh G, Hussain R, Bankole A, Singh S. Women with an unmet need for contraception in developing countries and their reasons for not using a method. Occasional Rep. 2007;37:5-40.

21. Cronin P, Ryan F, Coughlan M. Undertaking a literature review: a step-by-step approach. Br J Nurs. 2008;17(1):38-43.

22. Pace R, Pluye P, Bartlett G, Macaulay AC, Salsberg J, Jagosh J, Seller R. Testing the reliability and efficiency of the pilot Mixed Methods Appraisal Tool (MMAT) for systematic mixed studies review. Int J Nurs Stud. 2012;49(1):47-53.

23. Aartman $\mathrm{IH}$. The PICO (patient-intervention-comparison-outcome) question. Nederlands tijdschrift Voor Tandheelkunde. 2007:114(4):172-8.

24. Huang X, Lin J, Demner-Fushman D. In Evaluation of PICO as a knowledge representation for clinical questions. J Am Med Inform Assoc. 2006:2006:359-63.

25. Cooke A, Smith D, Booth A. Beyond PICO: the SPIDER tool for qualitative evidence synthesis. Qual Health Res. 2012;22:1435-43.
26. Davies KS. Formulating the evidence-based practice question: a review of the frameworks. Evid Based Libr Inf Pract. 2011;6(2):75-80.

27. Arksey H, O'Malley L. Scoping studies: towards a methodological framework Int J Soc Res Method. 2005;8(1):19-32.

28. Moher D, Liberati A, Tetzlaff J, Altman DG. Preferred reporting items for systematic reviews and meta-analyses: the PRISMA statement. Ann Intern Med. 2009;151(4):264-9.

29. Preferred Reporting Items for Systematic Reviews and Meta-Analyses PRISMA flow diagram. http://www.prisma-statement.org/. Accessed 28 Aug 2019.

30. Whittemore R, Knafl K. The integrative review: updated methodology. J Adv Nurs. 2005:52(5):546-53.

31. Hewitt-Taylor J. The essential guide to doing a health and social care literature review. Oxon: Routledge; 2017.

32. Aveyard $H$, Payne SA, Preston NJ. A post-graduate's guide to doing a literature review in health and social care. Oxford: Oxford University Press; 2016.

33. Booth A, Clarke M, Dooley G, Ghersi D, Moher D, Petticrew M, Stewart L. The nuts and bolts of PROSPERO: an international prospective register of systematic reviews. Syst Rev. 2012;1:2.

34. Boland A, Cherry G, Dickson R. Doing a systematic review: a student's quide. London: Sage; 2017

35. Bramer WM, de Jonge GB, Rethlefsen ML, Mast F, Kleijnen J. A systematic approach to searching: an efficient and complete method to develop literature searches. J Med Libr Ass. 2018;106(4):531.

36. Swift JK, Wampold BE. Inclusion and exclusion strategies for conducting meta-analyses. Psychother Res. 2018;28(3):356-66.

37. Hunter JE, Schmidt FL. Methods of meta-analysis: correcting error and bias in research findings. London: Sage; 2004.

38. Critical Appraisal Skills Programme CASP. https://casp-uk.net/wp-content uploads/2018/01/CASP-Qualitative-checklists-2018.pdf/. Accessed 28 Jun 2020

39. Moule P, Pontin D, Gilchrist M, Ingram R. Critical appraisal framework. http:// learntech.uwe.ac.uk/da/Defaul.aspx?oageid=1445. Accessed 28 Jun 2020.

40. Deitch J, Stark L. Adolescent demand for contraception and family planning services in low-and middle-income countries: a systematic review. Glob Public Health. 2019. https://doi.org/10.1080/17441692.2019.1583264.

41. Abera Y, Mengesha ZB, Tessema GA. Postpartum contraceptive use in Gondar town, Northwest Ethiopia: a community based cross-sectiona study. BMC Women's Health. 2015;15:19.

42. Abraha TH, Teferra AS, Gelagay AA. Postpartum modern contraceptive use in northern Ethiopia: prevalence and associated factors. Epidemiol Health. 2017:39:e2017012

43. Abraha TH, Belay HS, Welay GM. Intentions on contraception use and its associated factors among postpartum women in Aksum town, Tigray region, northern Ethiopia: a community-based cross-sectional study. Reprod Health. 2018;15(1):188

44. Gebremedhin AY, Kebede Y, Gelagay AA, Habitu YA. Family planning use and its associated factors among women in the extended postpartum period in Addis Ababa, Ethiopia. Contracept Reprod Med. 2018:3:1.

45. Dona A, Abera M, Alemu T, Hawaria D. Timely initiation of postpartum contraceptive utilization and associated factors among women of child bearing age in Aroressa District, Southern Ethiopia: a community based cross-sectional study. BMC Public Health. 2018;18:1100.

46. Berta M, Feleke A, Abate T, Worku T, Gebrecherkos T. Utilization and associated factors of modern contraceptives during extended postpartum period among women who gave birth in the last 12 months in Gondar Town Northwest Ethiopia. Ethiop J Health Sci. 2018;28(2):207-16.

47. Tegegn M, Arefaynie M, Tiruye TY. Unmet need for modern contraceptives and associated factors among women in the extended postpartum period in Dessie town, Ethiopia. Contracept Reprod Med. 2017;2:21.

48. Mengesha ZB, Worku AG, Feleke SA. Contraceptive adoption in the extended postpartum period is low in Northwest Ethiopia. BMC Pregnancy Childbirth. 2015;15:160.

49. Gejo NG, Anshebo AA, Dinsa LH. Postpartum modern contraceptive use and associated factors in Hossana town. PLoS ONE. 2019;14:e0217167.

50. Abraha TH, Gebrezgiabher BB, Aregawi BG, Belay DS, Tikue LT, Welay GM Predictors of postpartum contraceptive use in rural Tigray region, northern Ethiopia: a multilevel analysis. BMC Public Health. 2018;1:1017.

51. Chinaeke EE, Fan-Osuala C, Bathnna M, Ozigbu CE, Olakunde B, Ramadhani $\mathrm{HO}$, et al. Correlates of reported modern contraceptive use among 
postpartum HIV-positive women in rural Nigeria: an analysis from the MoMent prospective cohort study. Reprod Health. 2019;16:2.

52. Idowu A, Ogunsola OO, Ogunlaja O. Knowledge, determinants and unmet needs for postpartum family planning use among women attending immunization clinic at Bowen University Teaching Hospital, Ogbomoso, Oyo State, Nigeria. Afr J Med Med Sci. 2015;44(1):43-51.

53. Iliyasu Z, Galadanci HS, Danlami KM, Salihu HM, Aliyu MH. Correlates of postpartum sexual activity and contraceptive use in Kano, Northern Nigeria. Afr J Reprod Health. 2018;22(1):103-12.

54. Bwazi C, Maluwa A, Chimwaza A, Pindani M. Utilization of postpartum family planning services between six and twelve months of delivery at Ntchisi District Hospital, Malawi. Health. 2014;6(14):1724-37.

55. Thindwa D, Landes $M$, van Lettow M, Kanyemba A, Nkhoma E, Phiri H, et al. Pregnancy intention and contraceptive use among HIV-positive Malawian women at 4-26 weeks post-partum: a nested cross-sectional study. PLoS ONE. 2019;14(4):e0215947.

56. Achwoka D, Pintye J, McGrath CJ, Kinuthia J, Unger JA, Obudho N, Langat A, John-Stewart G, Drake AL. Uptake and correlates of contraception among postpartum women in Kenya: results from a national cross-sectional survey. Contraception. 2018;97(3):227-35.

57. Keesara S, Juma PA, Harper CC, Newmann SJ. Barriers to postpartum contraception: differences among women based on parity and future fertility desires. Cult Health Sex. 2018;20(3):247-61.

58. Sileo KM, Wanyenze RK, Lule H, Kiene SM. Determinants of family planning service uptake and use of contraceptives among postpartum women in rural Uganda. Int J Public Health. 2015;60(8):987-97.

59. Embafrash G, Mekonnen W. Level and correlates of unmet need of contraception among women in extended postpartum in Northern Ethiopia. Int J Reprod. 2019;2019:1-9.

60. Zapata LB, Murtaza S, Whiteman MK, Jamieson DJ, Robbins CL, Marchbanks PA, D'Angelo DV, Curtis KM. Contraceptive counseling and postpartum contraceptive use. Am J Obstet Gynecol. 2015;212(2):171-e1.

61. Hounton S, Winfrey W, Barros AJD, Askew I. Patterns and trends of postpartum family planning in Ethiopia, Malawi, and Nigeria: evidence of missed opportunities for integration. Glob Health Action. 2015;8(1):29738.

62. Lopez LM, Grey TW, Hiller JE, Chen M. Education for contraceptive use by women after childbirth. Cochrane Database Syst Rev. 2015. https://doi. org/10.1002/14651858.CD001863.pub4.

63. Naanyu V, Baliddawa J, Peca E, Karfakis J, Nyagoha N, Koech B. An examination of postpartum family planning in western Kenya: "I want to use contraception but I have not been told how to do so." Afr J Reprod Health. 2013;17(3):44-53.

64. Shah NJ, Pradhan P, Reddy AS, Joseph B. Contraceptive practices in newly married women in sub-urban Bangalore. Health PopulationPerspectives Issues. 2006;29(1):21-8.

65. Boardman LA, Desimone M, Allen RH. Barriers to completion of desired postpartum sterilization. R I Med J. 2013;96(2):32-4.

66. Stephenson R, Baschieri A, Clements S, Hennink M, Madise N. Contextual influences on modern contraceptive use in sub-Saharan Africa. Am J Public Health. 2007;97(7):1233-40.

67. Borda MR, Winfrey W, McKaig C. Return to sexual activity and modern family planning use in the extended postpartum period: an analysis of findings from seventeen countries. Afr J Reprod Health. 2010;14(4):72-9.

68. Gebreselassie T, Rutstein SO, Mishra V. Contraceptive use breastfeeding amenorrhea and abstinence during the postpartum period: an analysis of four countries. DHS Analytical Studies No. 14. Calverton, Maryland, USA: Macro International. 2008.

69. Susuman AS, Bado A, Lailulo YA. Promoting family planning use after childbirth and desire to limit childbearing in Ethiopia. Reprod Health. 2014;11(1):53.

70. Issaka Al, Agho KE, Renzaho AMN. Prevalence of key breastfeeding indicators in 29 sub-Saharan African countries: a meta-analysis of demographic and health surveys (2010-2015). BMJ Open. 2017;7(10):e014145.

71. Speizer IS, Fotso JC, Okigbo C, Faye CM, Seck C. Influence of integrated services on postpartum family planning use: a cross-sectional survey from urban Senegal. BMC Public Health. 2013;13(1):752.

72. Mehata S, Paudel YR, Mehta R, Dariang M, Poudel P, Barnett S. Unmet need for family planning in Nepal during the first two years postpartum. BioMed Res Int. 2014. https://doi.org/10.1155/2014/649567.
73. Ndugwa RP, Cleland J, Madise NJ, Fotso J-C, Zulu EM. Menstrual pattern, sexual behaviors, and contraceptive use among postpartum women in Nairobi urban slums. J Urban Health. 2011;88(2):341-55.

74. Rutaremwa G, Kabagenyi A, Wandera SO, Jhamba T, Akiror E, Nviri HL. predictors of modern contraceptive use during the postpartum period among women in Uganda: a population-based cross-sectional study. BMC Public Health. 2015;15(1):262.

75. Nigussie AT, Girma D, Tura G. Postpartum family planning utilization and associated factors among women who gave birth in the past 12 months, Kebribeyah Town, Somali Region, Eastern Ethiopia. JWomen's Health Care. 2016;5(340):2167-0420.

76. Wakefiled MA, Loken B, Hornik RC. Use of mass media campaigns to change health behaviour. Lancet. 2010;376(9748):1261-7.

77. Harries J, Lince N, Constant D, Hargey A, Grossman D. The challenges of offering public second trimester abortion services in South Africa: health care providers' perspectives. J Biosoc Sci. 2012;44(2):197-208.

78. Basinga P, Moore AM, Singh SD, Carlin EE, Birungi F, Ngabo F. Abortion incidence and postabortion care in Rwanda. Stud Fam Plann. 2012;43(1):11-20.

79. Evans E, Otieno-Masaba R, Eichleay M, McCarraher DO, Hainsworth G, Lane $C$, et al. Post-abortion care services for youth and adult clients in Kenya: a comparison of services, client satisfaction and provider attitudes. J Biosoc Sci. 2014;46(1):1.

80. Ayanore MA, Pavlova M, Groot W. Unmet reproductive health needs among women in some West African countries: a systematic review of outcome measures and determinants. Reprod Health. 2015;13(1):5.

81. Wai KM, Shibanuma A, Oo NN, Fillman TJ, Saw YM, Jimba M. Are husbands involving in their spouses'utilization of maternal care services?: a crosssectional study in Yangon, Myanmar. PLoS ONE. 2015;10(12):e0144135.

82. Keogh SC, Urassa M, Kumogola Y, Kalongoji S, Kimaro D, Zaba B. Postpartum contraception in northern Tanzania: patterns of use, relationship to antenatal intentions, and impact of antenatal counseling. Stud Fam Plan. 2015;46(4):405-22.

83. Ayiasi RM, Muhumuza C, Bukenya J, Orach CG. The effect of prenatal counselling on postpartum family planning use among early postpartum women in Masindi and Kiryandongo districts. Uganda Pan Afr Med J. 2015. https://doi.org/10.11604/pamj.2015.21.138.7026.

84. Sarnquist CC, Rahangdale L, Maldonado Y. Reproductive health and family planning needs among HIV-infected women in Sub-Saharan Africa. Curr HIV Res. 2013;11(2):160-8.

85. Ekabua JE, Ekabua KJ, Odusolu P, Iklaki CU, Agan TU, Etokidem AJ. Factors associated with contraceptive use and initiation of coital activity after childbirth. Open Acc J Contracept. 2010;1:85-91.

86. Barber SL. Family planning advice and postpartum contraceptive use among low-income women in Mexico. Int Fam Plan Perspect. 2007;33:6-12.

87. Lagro M, Liche A, Mumba T, Ntebeka R, van Roosmalen J. Postpartum care attendance at a rural district hospital in Zambia. Trop Doct. 2006;36(4):205-8.

88. Do M, Hotchkiss D. Relationships between antenatal and postnatal care and post-partum modern contraceptive use: evidence from population surveys in Kenya and Zambia. BMC Health Serv Res. 2013;13(1):6.

89. Moore Z, Pfitzer A, Gubin R, Charurat E, Elliott L, Croft T. Missed opportunities for family planning: an analysis of pregnancy risk and contraceptive method use among postpartum women in 21 low-and middle-income countries. Contraception. 2015:92(1):31-9.

90. World Bank Sub-Saharan Africa: The World Bank. https://data.worldbank. org/region/sub-saharan-africa. Accessed 24 Aug 2019.

91. Do M, Kurimoto N. Women's empowerment and choice of contraceptive methods in selected African countries. Int Perspect Sex Reprod Health. 2012:38:23-33.

92. Alkema L, Kantorova V, Menozzi C, Biddlecom A. A National, regional, and global rates and trends in contraceptive prevalence and unmet need for family planning between 1990 and 2015: a systematic and comprehensive analysis. Lancet. 2013;381(9878):1642-52.

\section{Publisher's Note}

Springer Nature remains neutral with regard to jurisdictional claims in published maps and institutional affiliations. 